Washington University School of Medicine Digital Commons@Becker

Open Access Publications

2008

\title{
Laparoscopic retroperitoneal lymph node dissection for low-stage testicular cancer
}

T. A. Skolarus

Washington University School of Medicine in St. Louis

S. B. Bhayani

Washington University School of Medicine in St. Louis

H. C. Chang

Washington University School of Medicine in St. Louis

S. B. Brandes

Washington University School of Medicine in St. Louis

A. S. Kibel

Washington University School of Medicine in St. Louis

See next page for additional authors

Follow this and additional works at: https://digitalcommons.wustl.edu/open_access_pubs

Please let us know how this document benefits you.

\section{Recommended Citation}

Skolarus, T. A.; Bhayani, S. B.; Chang, H. C.; Brandes, S. B.; Kibel, A. S.; Landman, J.; and Figenshau, R. S., "Laparoscopic retroperitoneal lymph node dissection for low-stage testicular cancer." Journal of Endourology. 22, 7. 1485-1490. (2008).

https://digitalcommons.wustl.edu/open_access_pubs/2906

This Open Access Publication is brought to you for free and open access by Digital Commons@Becker. It has been accepted for inclusion in Open Access Publications by an authorized administrator of Digital Commons@Becker. For more information, please contact vanam@wustl.edu. 


\section{Authors}

T. A. Skolarus, S. B. Bhayani, H. C. Chang, S. B. Brandes, A. S. Kibel, J. Landman, and R. S. Figenshau 


\title{
Laparoscopic Retroperitoneal Lymph Node Dissection for Low-Stage Testicular Cancer
}

\author{
T.A. Skolarus, M.D., ${ }^{1}$ S.B. Bhayani, M.D., ${ }^{1}$ H.C. Chiang, M.D., Ph.D., ${ }^{1}$ S.B. Brandes, M.D., ${ }^{1}$ \\ A.S. Kibel, M.D., ${ }^{1}$ J. Landman, M.D., ${ }^{2}$ and R.S. Figenshau, M.D. ${ }^{1}$
}

\begin{abstract}
Background and Purpose: Current management options for low-stage mixed malignant germ-cell testicular tumors (MMGCT) after radical orchiectomy include surveillance, chemotherapy, or retroperitoneal lymph node dissection (RPLND). The open RPLND is the surgical gold standard and has been duplicated laparoscopically with confirmed diagnostic effectiveness; however, its therapeutic oncologic value in MMGCT has never been proven. We present our laparoscopic RPLND (L-RPLND) data for low-stage MMGCT and paratesticular rhabdomyosarcoma.

Patients and Methods: Retrospective chart reviews were performed for patients who underwent L-RPLND at our institution for low clinical stage MMGCT and paratesticular rhabdomyosarcoma from May 2003 to December 2007. Patient data were compiled for surgical and clinical variables.

Results: A total of 26 L-RPLND procedures were completed, 3 for paratesticular rhabdomyosarcoma. Mean operative time was 250 minutes (range 176-369 min); estimated blood loss was $145 \mathrm{~mL}$ (range 50-500 mL); lymph node count was 23.8 (range 8-48); and hospital stay was 1.5 days (range 1-3 d). Four patients underwent postchemotherapy L-RPLND for residual nodes $(1.1-2.9 \mathrm{~cm})$. There were no conversions to an open procedure, blood transfusions, or operative complications. Chemotherapy was instituted in five of six patients with pathologic stage II disease. Mean follow-up was 23.7 months without retroperitoneal disease recurrence.

Conclusion: L-RPLND as a diagnostic and therapeutic tool provides the benefits of a minimally invasive approach to MMGCT. It is the procedure of choice at our institution for low-stage MMGCT and paratesticular rhabdomyosarcoma.
\end{abstract}

\section{Introduction}

$\mathbf{T}$

HE CURRENT MANAGEMENT of low-stage mixed malignant germ-cell testicular tumors (MMGCT) after radical orchiectomy consists of several options including an intense surveillance protocol, platinum-based chemotherapy, or modified template retroperitoneal lymph node dissection (RPLND). With regard to surgery, laparoscopic RPLND (LRPLND) has demonstrated effectiveness as a retroperitoneal staging tool. ${ }^{1-3}$ Recently, however, the L-RPLND has duplicated open RPLND using full retroaortic and retrocaval dissections with multi-institutional evidence that demonstrates potential oncologic efficacy. ${ }^{1,4}$ Given the $30 \%$ incidence of metastatic disease in the retroperitoneum for low-stage MMGCT, 5,6 $70 \%$ of patients will undergo unnecessary therapy. Attempts to minimize morbidity and long-term therapeutic consequences are essential.
The open RPLND is considered the surgical gold standard, ${ }^{5}$ although its morbidity may intimidate patients who are considering a laparoscopic approach. This perception could change, because a recent report on the short-term morbidity of the open procedure demonstrated improved operative times, blood loss, and length of stay at a high-volume center. ${ }^{7}$

Laparoscopy, however, has become the standard of care in various urologic oncology treatment regimens with demonstrated efficacy, decreased morbidity, and improved patient satisfaction. ${ }^{8,9}$ L-RPLND has demonstrated improved convalescence and quality of life compared with open RPLND. ${ }^{10,11}$ In similar fashion, a report on robot-assisted LRPLND will continue to increase the minimally invasive nature of the procedure. ${ }^{12}$

In a comprehensive review of the current status of LRPLND, ${ }^{13}$ the strengths and limitations of the approach were portrayed and indicated that longer oncologic follow-up is

${ }^{1}$ Division of Urologic Surgery, Washington University in St. Louis, St. Louis, Missouri.

${ }^{2}$ Department of Urology, Columbia University School of Medicine, New York, New York. 


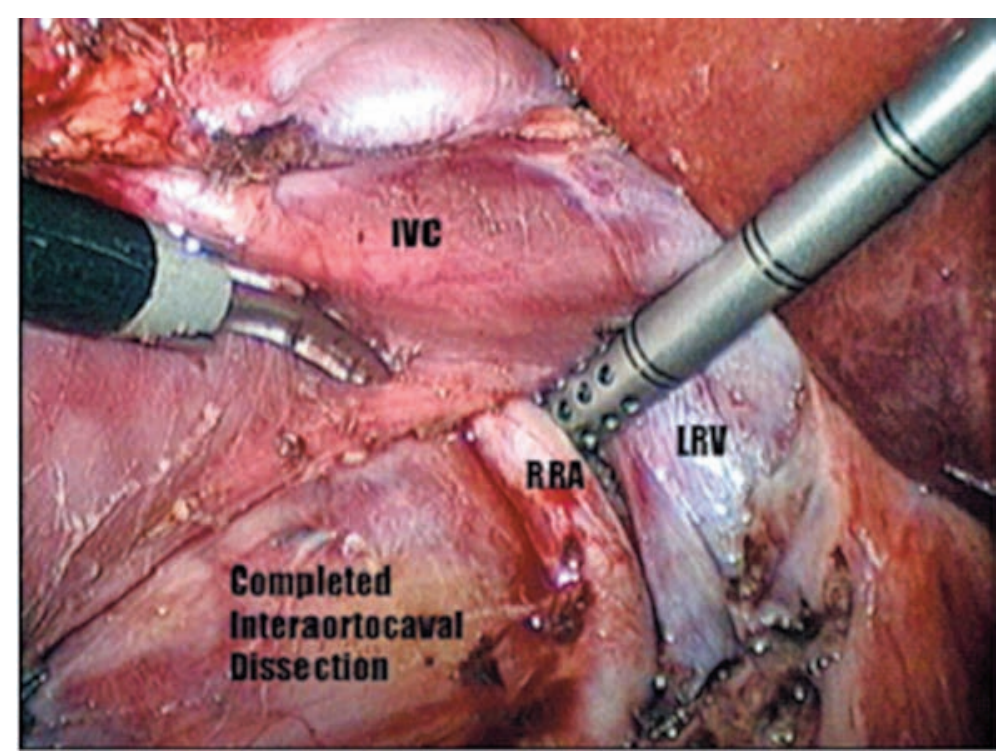

FIG. 1. Interaortocaval dissection. Note the complete excision of lymph tissue in the region during this right L-RPLND.

necessary for this promising approach. Considering the potential long-term adverse effects of primary chemotherapy, including cardiovascular disease and secondary malignancy reported to increase in testicular cancer survivors, ${ }^{14,15}$ treatment opportunities with minimal morbidity should be explored. We present our experience with L-RPLND for lowstage testicular cancer at Washington University with 2 years of follow-up.

\section{Patients and Methods}

Retrospective chart reviews were performed for patients who underwent L-RPLND at our institution for low-stage (I,
IIA/B) MMGCT and paratesticular rhabdomyosarcoma from May 2003 to December 2007. Staging was performed using the 2002 American Joint Committee on Cancer guidelines. The Human Studies Committee at Washington University approved the research protocol. Twenty-six patients were identified. Patient data were compiled for surgical and clinical variables, including: pre-orchiectomy tumor markers (beta-human chorionic gonadotropin [ $\beta$-HCG], $\alpha$-fetoprotein [AFP] and lactate dehydrogenase), orchiectomy data, LRPLND operative times, estimated blood loss (EBL), length of hospital stay, number of resected lymph nodes with pathologic analysis, chemotherapeutic regimens, ejaculation status, and imaging results.

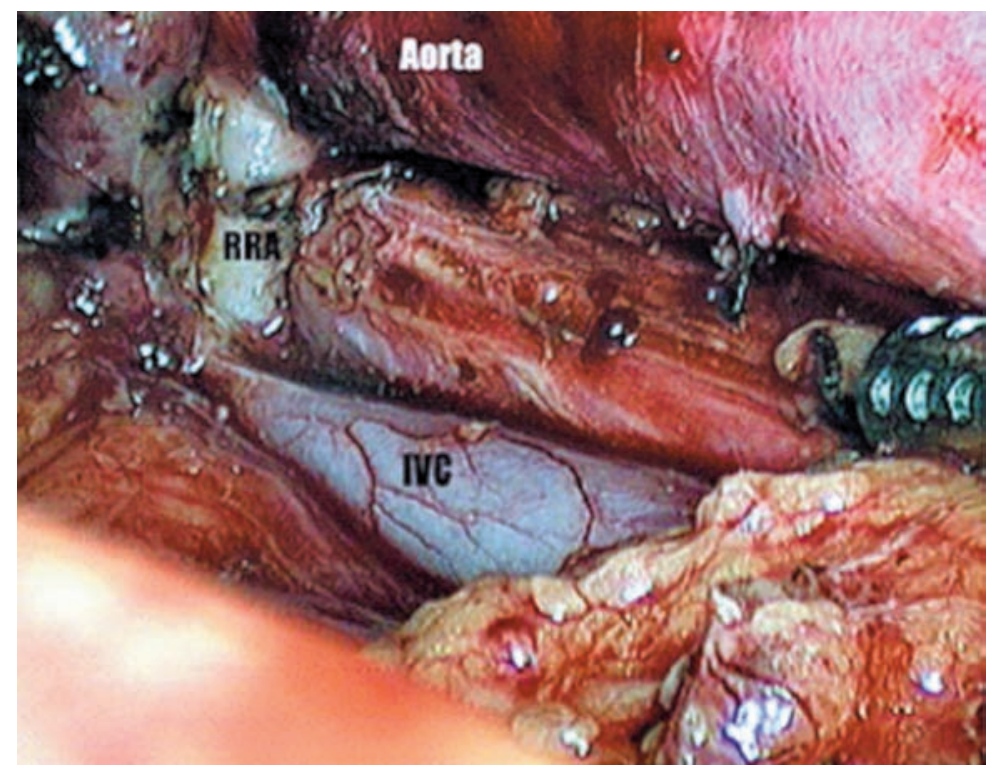

FIG. 2. Para-aortic dissection. Similar clearing of lymph tissue during left L-RPLND. 
Table 1. Patient and Operative Data for L-RPLND

\begin{tabular}{lc}
\hline Mean age (years) & 31 \\
Orchiectomy & 12 \\
Right & 14 \\
Left & \\
Pathology & 2 \\
$\quad$ Pure embryonal & 1 \\
Pure mature teratoma & 1 \\
Seminoma teratoma & 3 \\
Rhabdomyosarcoma & \\
Mixed-19 & $19(100 \%)$ \\
$\quad$ With embryonal & $9(47 \%)$ \\
$\quad$ With seminoma & \\
$\quad$ With teratoma & $9(47 \%)$ \\
$\quad$ Mature & $11(58 \%)$ \\
$\quad$ Immature & $10(53 \%)$ \\
$\quad$ With yolk sac & $14 / 23(61 \%)$ \\
ITGCN & $7 / 23(30 \%)$ \\
LV invasion & $250(176-369)$ \\
Mean operative time (minutes) & \\
(range) & $145(50-500)$ \\
Median EBL (mL) (range) & $1.5(1-3)$ \\
Mean hospital days (range) & $23.8(8-48)$ \\
Mean lymph nodes (range) & $23.7(3.2-55.3)$ \\
Follow-up (months) (range) &
\end{tabular}

L-RPLND = laparoscopic retroperitoneal lymph node dissection; ITGCN = intratubular germ-cell neoplasia; LV = lymphovascular; $\mathrm{EBL}=$ estimated blood loss.

Before L-RPLND, 19 clinical stage I patients with MMGCT with normalization of tumor markers after orchiectomy and 4 postchemotherapy patients with residual masses were identified. Most clinical stage I patients with MMGCT had embryonal carcinoma and/or lymphovascular invasion in the orchiectomy specimen. Three L-RPLNDs were performed for paratesticular rhabdomyosarcoma, as ipsilateral RPLND is recommended in adolescents to further stage and manage the disease. ${ }^{16}$

There were no conversions to open RPLND and all patients without suspicious nodal involvement underwent unilateral nerve-sparing modified template dissections as described by Donohue and associates. ${ }^{17}$ Full retroaortic and retrocaval dissections were undertaken in left and right dissections, respectively, with interaortocaval node extraction in each case (Figs. 1 and 2). The Harmonic Scalpel (Ethicon EndoSurgery Inc, Cincinnati, $\mathrm{OH}$ ) and Ligasure (Valleylab, Boulder, $\mathrm{CO}$ ) devices were used for the majority of the dis- sections to limit clip placement and subsequent artifact on follow-up imaging.

Suspicious nodes in patients with clinical stage I disease were sent for frozen analysis. If positive, before 2006, the dissection was still performed in a similar fashion, and the option of chemotherapy was proposed for pathologic stage II disease. Currently, on discovery of positive nodal status intraoperatively, a full bilateral dissection is performed. This has been completed in one patient with metastatic germ-cell tumor on frozen section analysis.

Follow-up of the patients consisted of history and physical examination, tumor markers, and chest radiography at 3-month intervals, with periodic CT imaging. After approximately 2 years, visit intervals were increased to 6 months and then annually according to physician preference. Variation in the recommended follow-up pattern was observed as some patients received follow-up at outside institutions.

\section{Results}

L-RPLND was successfully completed in all 26 patients. Patient and operative data are shown in Table 1 . There were no conversions to an open procedure, blood transfusions, or operative complications. Mean operative time was $250 \mathrm{~min}-$ utes (range 176-369 min), EBL $145 \mathrm{~mL}$ (range 50-500 mL), lymph node count 23.8 (range 8-48), and hospital stay 1.5 days (range 1-3 d). Mean follow-up was 23.7 months (range 3.2-55.3 months) without retroperitoneal disease recurrence to date.

Postoperative complications included constipation and emesis, one; lymphocele, four; deep vein thrombosis and pulmonary embolism, one; chylous ascites, one; and ejaculatory dysfunction, three.

All three patients with paratesticular rhabdomyosarcoma received chemotherapy with or without radiation as recommended by the Intergroup Rhabdomyosarcoma Study Group $^{16}$ without recurrence to date.

Chemotherapy was instituted in five of six patients with pathologic stage IIA MMGCT disease (Table 2) who comprised $32 \%$ of the clinical stage I population. Four patients underwent postchemotherapy L-RPLND for residual nodes $(1.1 \mathrm{~cm}, 1.2 \mathrm{~cm}, 2.1 \mathrm{~cm}, 2.9 \mathrm{~cm})$ without retroperitoneal recurrence to date (Table 3 ). The patient with a $1.2 \mathrm{~cm}$ mass who underwent a unilateral dissection demonstrates slowly rising AFP and $\beta$-HCG (both within normal limits) with negative imaging studies at 17 months of follow-up.

Table 2. Pathologic Stage IIA after L-RPLND

\begin{tabular}{|c|c|c|c|c|}
\hline $\begin{array}{l}\text { Orchiectomy } \\
\text { pathology }\end{array}$ & $\begin{array}{l}\text { Retroperitoneal pathology } \\
\text { (positive total nodes) }\end{array}$ & Treatment & Follow-up & Recurrence \\
\hline S, MT & 2/19-EC, Ch, MT & $\mathrm{EP} \times 4$ & $50.2 \mathrm{mos}$ & None \\
\hline $\mathrm{EC}$ & $3 / 26-\mathrm{GCT}$ & $\mathrm{BEP} \times 3$ & $17 \mathrm{mos}$ & None \\
\hline S, EC, IMT, MT & $1 / 30-S$ & Surveillance & $31.3 \mathrm{mos}$ & None \\
\hline $\mathrm{EC}, \mathrm{YS}$ & $1 / 39-\mathrm{GCT}$ & $\mathrm{EP} \times 2$ & 13 mos & None \\
\hline $\mathrm{EC}, \mathrm{YS}$ & $2 / 20-\mathrm{GCT}$ & $\mathrm{EP} \times 2$ & $6.6 \operatorname{mos}$ & None \\
\hline S, EC, IMT, MT & $3 / 32-S$ & $\mathrm{BEP} \times 2$ & $4.3 \mathrm{mos}$ & None \\
\hline
\end{tabular}

$\mathrm{S}=$ seminoma; $\mathrm{MT}=$ mature teratoma; $\mathrm{EC}=$ embryonal carcinoma; $\mathrm{Ch}=$ choriocarcinoma; $\mathrm{EP}=$ etoposide; $\mathrm{P}=$ platinum-based chemotherapy regimen; no lymphovascular invasion in any specimens; GCT = metastatic germ cell tumor not specified; $\mathrm{B}=$ bleomycin; IMT $=$ immature teratoma; YS = yolk sac. 
TAble 3. Post-Chemotherapy L-RPLNDa

\begin{tabular}{|c|c|c|c|c|c|c|c|}
\hline $\begin{array}{l}\text { Residual } \\
\text { mass }\end{array}$ & $\begin{array}{l}\text { OR time } \\
\text { (min) }\end{array}$ & $U / B$ & $\begin{array}{l}E B L \\
(m L)\end{array}$ & Pathology & $H D$ & $\begin{array}{c}\text { Follow-up } \\
\text { (months) }\end{array}$ & Recurrence \\
\hline $1.1 \mathrm{~cm}$ & 317 & $\mathrm{U}$ & 100 & 3/34 MT & 1 & 10.4 & None \\
\hline $1.2 \mathrm{~cm}$ & 200 & $\mathrm{U}$ & 50 & 1/37 MT & 1 & 17.3 & $\begin{array}{l}\text { Rising, normal range } \\
\text { AFP / } \beta \text {-HCG; no } \\
\text { radiographic } \\
\text { evidence of } \\
\text { recurrence }\end{array}$ \\
\hline $2.1 \mathrm{~cm}$ & 369 & B & 150 & $2 / 35 \mathrm{~S}$ & 1 & 5.8 & None \\
\hline $2.9 \mathrm{~cm}$ & 214 & $\mathrm{U}$ & 75 & 3/27 MT & 1 & 17.5 & None \\
\hline
\end{tabular}

aNo further chemotherapy administered.

$\mathrm{OR}=$ operating room; $\mathrm{U} / \mathrm{B}=$ unilateral or bilateral dissection; $\mathrm{EBL}=$ estimated blood loss; $\mathrm{HD}=$ hospital days; $\mathrm{MT}=$ mature teratoma; $\mathrm{AFP} / \beta$-HCG $=\alpha$-fetoprotein $/ \beta$ human chorionic gonadotropin; $\mathrm{S}=$ seminoma .

\section{Discussion}

L-RPLND has been performed at our institution since 2003 for persons with low-stage MMGCT of the testis. None of the patients with pathologic stage I disease have demonstrated recurrent disease in the retroperitoneum, consistent with previous reports ${ }^{1-4}$ of L-RPLND as an accurate diagnostic staging tool. The ability to appropriately stage the retroperitoneum is evidenced by lack of retroperitoneal recurrence, although the oncologic efficacy of the procedure may be questioned, given that five of six patients with pathologic stage II disease underwent chemotherapy. The solitary patient undergoing surveillance demonstrates no recurrence at 31.3 months ( 1 of 30 lymph nodes with microscopic metastatic seminoma).

It has been necessary for institutions using advanced laparoscopic techniques to pool data on the limited numbers of patients with pathologic stage II disease undergoing surveillance to potentially demonstrate surgical equivalence. Hamilton and Finelli ${ }^{13}$ recently reviewed the status of L-RPLND and, although the technique has significant potential, the long-term oncologic data are not sufficient for comparison with the open procedure. In the transition from a staging tool to a therapeutic option, chemotherapy has continued to be instituted for pathologic stage II disease, thus clouding the true effectiveness of the procedure. The review cites benefits of decreased operative time, cost, and morbidity; however, if an inadequate dissection is performed, these are negated.

Our current practice is a full bilateral dissection in the setting of intraoperative nodal positivity along with complete evacuation of lymph tissue posterior to the great vessels, similar to the open procedure. The open RPLND has demonstrated, in a randomized fashion, efficacy in eradicating retroperitoneal disease in patients with pathologic stage II disease; surveillance and chemotherapy are used only when relapse occurs (50\% of patients) with similar cure rates. ${ }^{18}$

Given the duplication of the open technique, ${ }^{4}$ we and others offer potential oncologic efficacy similar to the open procedure, although this is yet unproven. Thus, the status of recommending L-RPLND at laparoscopic institutions using advanced laparoscopic techniques as a sole treatment for pathologic stage II disease remains unclear. Indeed, longer follow-up of the limited numbers of patients forgoing chemotherapy in the setting of positive lymph nodes needs to be conducted as well as future studies on the efficacy of LRPLND alone for pathologic stage II disease.
L-RPLND in postchemotherapy patients has an increased complication rate ${ }^{19}$; therefore, patient selection is important. We performed postchemotherapy L-RPLND in four patients for 1.1 to $2.9 \mathrm{~cm}$ masses. All patients had three cycles of bleomycin, etoposide, and platinum chemotherapy before surgery and underwent uncomplicated procedures, with discharge on postoperative day 1. Lymph nodes resected ranged from 27 to 37 . Three specimens demonstrated mature teratoma; the other was metastatic seminoma, although the original tumor did contain elements of seminoma, teratoma, and embryonal carcinoma. Mean operative time was 275 minutes. Mean follow-up is 12.7 (5.8-17.5) months.

The single postoperative complication occurred after a bilateral dissection for a $2.1 \mathrm{~cm}$ left para-aortic mass in a patient with a mildly elevated AFP level. A large lymphocele developed in the patient that caused inferior vena caval obstruction and bilateral deep vein thromboses as well as pulmonary embolism. After lymphocele drainage, anticoagulation, and various temporary venous filter placements, the patient recovered and is disease free.

Also, one patient demonstrates rising AFP and $\beta$-HCG levels (both within normal limits) with negative imaging at 17 months of follow-up after undergoing a left modified template L-RPLND for a $1.2 \mathrm{~cm}$ residual mass; pathologic evaluation demonstrated metastatic teratoma in 1 of 37 lymph nodes. These data suggest postchemotherapy L-RPLND is feasible; however, the risk of postoperative complications may be increased, and close follow-up is necessary.

Ipsilateral RPLND is currently recommended as part of the staging process in adolescents with paratesticular rhabdomyosarcoma. ${ }^{16}$ It also guides further treatment strategies based on recommendations from the Intergroup Rhabdomyosarcoma Study Group. Pathologic findings at L-RPLND in two of three patients were negative for malignancy; however, one patient did demonstrate metastatic embryonal rhabdomyosarcoma in 3 of 48 lymph nodes, necessitating radiation therapy in addition to standard chemotherapy (vincristine, actinomycin-D, and cyclophosphamide) with no evidence of metastatic disease at 21.1 months follow-up.

To our knowledge, only one other report demonstrates LRPLND as an option for children with paratesticular rhabdomyosarcoma. ${ }^{20}$ Although a rare tumor, we recommend staging the retroperitoneum in cases of adolescent paratesticular rhabdomyosarcoma using L-RPLND.

Limitations of our study include its retrospective nature 
and the limited 2-year duration of follow-up. Long-term oncologic data collection will be necessary as well as withholding chemotherapy in pathologic stage II patients; our series only contains one such person. We do, however, confirm the feasibility of the procedure at an experienced laparoscopic center with minimal perioperative morbidity and hospital stay.

\section{Conclusion}

L-RPLND as a diagnostic and therapeutic tool provides the benefits of a minimally invasive approach to MMGCT; however, the oncologic efficacy of L-RPLND continues to need further investigation. It is the procedure of choice at our institution for low-stage MMGCT and paratesticular rhabdomyosarcoma. In selected patients, L-RPLND is also safely used following chemotherapy. Further multi-institutional efforts are needed to conclusively demonstrate the efficacy of advanced, minimally invasive treatments for patients with testis cancer.

\section{Acknowledgment}

We thank Ryan Bowman, M.D., for contributions to the data collection.

\section{References}

1. Nielsen ME, Lima G, Schaeffer EM, Porter J, Cadeddu JA, Tuerk I, Kavoussi LR. Oncologic efficacy of laparoscopic RPLND in treatment of clinical stage I nonseminomatous germ cell testicular cancer. Urology 2007;70:1168-1172.

2. Albqami N, Janetschek G. Laparoscopic retroperitoneal lymph-node dissection in the management of clinical stage I and II testicular cancer. J Endourol 2005;19:683-692.

3. Bhayani SB, Ong A, Oh WK, Kantoff PW, Kavoussi LR. Laparoscopic retroperitoneal lymph node dissection for clinical stage I nonseminomatous germ cell testicular cancer: A longterm update. Urology 2003;62:324-327.

4. Allaf ME, Bhayani SB, Link RE, Schaeffer EM, Varkarakis JM, Shadpour P, Lima G, Kavoussi ER. Laparoscopic retroperitoneal lymph node dissection: Duplication of open technique. Urology 2005;65:575-577.

5. Foster RS, Donohue JP. Retroperitoneal lymph node dissection for the management of clinical stage I nonseminoma. J Urol 2000;163:1788-1792.

6. Donohue JP, Thornhill JA, Foster RS, Rowland RG, Bihrle R. Primary retroperitoneal lymph node dissection in clinical stage A non-seminomatous germ cell testis cancer. Review of the Indiana University experience 1965-1989. Br J Urol 1993;71:326-335.

7. Beck SD, Peterson MD, Bihrle R, Donohue JP, Foster RS. Short-term morbidity of primary retroperitoneal lymph node dissection in a contemporary group of patients. J Urol 2007;178:504-506.

8. McDougall E, Clayman RV, Elashry OM. Laparoscopic radical nephrectomy for renal tumor: The Washington University experience. J Urol 1996;155:1180-1185.

9. Winfield HN, Donovan JF, Lund GO, Kreder KJ, Stanley KE, Brown BP, Loening SA, Clayman RV. Laparoscopic partial nephrectomy: Initial experience and comparison to the open surgical approach. J Urol 1995;153:1409-1414.

10. Hobisch A, Tonnemann J, Janetschek G. Morbidity and quality of life after open versus laparoscopic retroperitoneal lymphadenectomy for testicular tumour - the patient's view. In:
Jones W, Appleyard I, Hamden P, Joffe J, eds. Germ Cell Tumours VI. London: John Libbey \& Co, 1998, p 277.

11. Poulakis V, Skriapas K, de Vries R, Dillenburg W, Ferakis N, Witzsch U, Becht E. Quality of life after laparoscopic and open retroperitoneal lymph node dissection in clinical Stage I nonseminomatous germ cell tumor: A comparison study. Urology 2006;68:154-160.

12. Davol P, Sumfest J, Rukstalis D. Robotic-assisted laparoscopic retroperitoneal lymph node dissection. Urology 2006; 67:199.

13. Hamilton RJ, Finelli A. Laparoscopic retroperitoneal lymph node dissection for nonseminomatous germ-cell tumors: Current status. Urol Clin North Am 2007;34:159-169.

14. van den Belt-Dusebout AW, de Wit R, Gietema JA, et al. Treatment-specific risks of second malignancies and cardiovascular disease in 5-year survivors of testicular cancer. J Clin Oncol 2007;25:4370-4378.

15. Travis LB, Fosså SD, Schonfeld SJ, et al. Second cancers among 40,576 testicular cancer patients: Focus on long-term survivors. J Natl Cancer Inst 2005;97:1354-1365.

16. Wiener ES, Anderson JR, Ojimba JI, et al. Controversies in the management of paratesticular rhabdomyosarcoma: Is staging retroperitoneal lymph node dissection necessary for adolescents with resected paratesticular rhabdomyosarcoma? Semin Pediatr Surg 2001;10:146-152.

17. Donohue JP, Thornhill JA, Foster RS, Rowland RG, Bihrle R. Retroperitoneal lymphadenectomy for clinical stage A testis cancer (1965 to 1989): Modifications of technique and impact on ejaculation. J Urol 1993;149:237-243.

18. Williams SD, Stablein DM, Einhorn LH, et al. Immediate adjuvant chemotherapy versus observation with treatment at relapse in pathological stage II testicular cancer. N Engl J Med 1987;317:1433-1438.

19. Palese MA, Su LM, Kavoussi LR. Laparoscopic retroperitoneal lymph node dissection after chemotherapy. Urology 2002;60:130-134.

20. Ost MC, VanderBrink BA, Kavoussi LR. Laparoscopic retroperitoneal lymph node dissection (LRLND) for highrisk pediatric patients with para-testicular rhabdomyosarcoma. MP21-07, WCE 2006.

Address reprint requests to:
Ted A. Skolarus, M.D.
Washington University School of Medicine
4960 Children's Place
Campus Box \# 8242
Saint Louis, MO 63110

E-mail: skolarust@wudosis.wustl.edu

$\begin{aligned} & \text { Abbreviations Used } \\ & \mathrm{CT}=\text { computed tomography } \\ & \mathrm{AFP}=\alpha \text {-fetoprotein } \\ & \beta-\mathrm{HCG}=\beta \text {-human chorionic gonadotropin } \\ & \mathrm{CT}=\text { computed tomography } \\ & \mathrm{EBL}=\text { estimated blood loss } \\ & \mathrm{L}-\mathrm{RPLND}= \text { laparoscopic retroperitoneal lymph node } \\ & \text { dissection } \\ & \mathrm{MMGCT}= \text { mixed malignant germ-cell testicular } \\ & \text { tumors } \\ & \mathrm{RPLND}= \text { retroperitoneal lymph node dissection }\end{aligned}$


